Flávia Santos Medina a

Maria Zoreide Britto Maia ${ }^{\text {b }}$

\title{
A subnotificação de LER/DORT sob a ótica de profissionais de saúde de Palmas, Tocantins
}

\author{
Underreporting of repetitive strain injuries/work-related \\ musculoskeletal disorders (RSI/WMSDs) from the perspective of \\ healthcare workers from Palmas, Tocantins, Brazil
}

\footnotetext{
a Secretaria de Estado da Saúde do Tocantins, Superintendência de Vigilância, Promoção e Proteção à Saúde, Diretoria de Vigilância Ambiental e Saúde do Trabalhador. Palmas, TO, Brasil.

${ }^{\mathrm{b}}$ Universidade Federal do Tocantins, Mestrado em Ciências da Saúde. Palmas, TO, Brasil.
}

\section{Contato:}

Flávia Santos Medina

E-mail:

fafamedina@hotmail.com

As autoras declaram que este trabalho não foi subvencionado e que não há conflitos de interesses.

Este trabalho é baseado na dissertação de mestrado de Flávia Santos Medina que teve como título "Análise dos fatores relacionados à subnotificação do agravo LER/DORT no SINAN NET em Palmas/TO", defendida em 2012 na Universidade Federal do Tocantins.

Trabalho não apresentado em reunião científica.

Recebido: 17/07/2014

Revisado: 20/12/2015

Aprovado: 21/12/2015

\section{Resumo}

Objetivo: este estudo analisa os elementos que influenciam a subnotificação do agravo LER/DORT no Sistema de Informação de Agravos de Notificação (Sinan) a partir da percepção dos profissionais que atuam na Rede de Serviços Sentinela em Saúde do Trabalhador na cidade de Palmas (TO). Método: pesquisa de natureza qualitativa, realizada com 21 profissionais de saúde que atendem pacientes com possíveis diagnósticos de LER/DORT ou que realizam a notificação desse agravo nas unidades sentinelas em saúde do trabalhador. Os dados foram coletados entre setembro e novembro de 2011 por meio de entrevistas semiestruturadas e analisados a partir da análise de conteúdo de Bardin. Resultados: entre os principais fatores relacionados à subnotificação das LER/DORT em Palmas, destacaram-se nos relatos dos participantes as dúvidas apresentadas pelos profissionais na identificação do agravo, as indefinições e desconhecimento do papel de cada profissional na identificação e notificação do agravo, a insuficiência do trabalho em equipe e a desvalorização da notificação por parte de alguns profissionais, associada ao desconhecimento da finalidade desses dados. Conclusões: essa situação assinala para a necessidade de qualificação dos profissionais em um processo de formação continuada, de modo a fomentar o trabalho em equipe que incorpore tanto discussões sobre as LER/DORT quanto em relação à importância da notificação no banco de dados do Sistema Único de Saúde (SUS).

Palavras-chave: LER/DORT; notificação; saúde do trabalhador; sistemas de informação, Sinan.

\begin{abstract}
Objective: to analyze the elements that influence underreporting of repetitive strain injuries/work-related musculoskeletal disorders (RSI/WMSDs) at the Brazilian notifiable diseases information system (SINAN), from the perspective of the healthcare workers from the Occupational Health Sentinel Service Network. Method: qualitative research with 21 healthcare workers who looked after patients with possible diagnosis of RSI/WMSD or who notified these diseases at the sentinel units in the city of Palmas (TO), Brazil. Data were collected from September to November 2011 through semi-structured interviews and analysed using Bardin's content analysis. Results: Among the main factors related to RSI/WMSDs underreporting in Palmas, the following are emphasized by the participants: the professionals' hesitation in identifying the injury; the lack of definition or knowledge regarding the role of each professional in identifying and reporting the injury; the insufficient team work; the way some healthcare workers undervalue notifications coupled with their unfamiliarity regarding the data purpose. Conclusions: this situation points towards the need for continuously training healthcare workers in a way to foster teamwork that includes discussions on both RSI/WMSDs and the importance of notifying them to the Brazilian Unified Health System (SUS) database.
\end{abstract}

Keywords: RSI/WMSDs; notifiable diseases; occupational health; information systems; SINAN. 


\section{Introdução}

As lesões por esforços repetitivos/distúrbios osteomusculares relacionados ao trabalho (LER/DORT) não são doenças recentes, porém representam, na atualidade, um grave problema socioeconômico e de saúde pública no Brasil, em razão da extensa população acometida e da incidência crescente. Outros fatores contribuintes para a relevância desses agravos referem-se à variedade de setores da economia impactados e à complexidade clínica, que resultam em: alto custo de tratamento; incapacidade gerada a muitos trabalhadores, representada por baixa qualidade de vida dos incapacitados; perda de produtividade e dias de trabalho; e custos com pagamentos de benefícios previdenciários ${ }^{1-3}$.

Estudo realizado por Souza e Santana ${ }^{3}$ no município de Salvador, em 2008, apontou que os benefícios concedidos pela Previdência Social a trabalhadores integrantes do Regime Geral (RGPS) com doenças musculoesqueléticas na região cervical e/ ou membros superiores corresponderam a $32 \%$ de todos aqueles relacionados ao trabalho, o que demonstra sua importância para a saúde pública. Segundo Scopel et al. ${ }^{4}$, no Brasil foram pagos 981,4 milhões de reais em auxílio-doença a 25 mil bancários afastados do trabalho por LER/DORT, entre os anos de 2000 e 2005. A média de tempo de afastamento desses trabalhadores foi de um ano e meio, que somados totalizam 14,9 milhões de dias sem trabalhar. Calcula-se que, para cada grupo de 10 mil trabalhadores, 520 bancários foram afastados por LER/DORT entre 2000 e $2004^{4}$.

Souza e Santana $^{3}$ apresentaram dados do National Research Council/Institute of Medicine, os quais mostram que nos Estados Unidos, custos com pagamentos de compensação por dias de trabalho perdidos por doenças musculoesqueléticas relacionadas ao trabalho variaram de 13 a 20 bilhões de dólares anualmente. Esses valores podem atingir 45 a 54 bilhões de dólares se forem adicionados os custos indiretos, representados por perda de renda e perda de produtividade.

A institucionalização da Política de Saúde do Trabalhador no Brasil vem sendo desenvolvida desde a Constituição Federal de 1988, que incorporou a saúde do trabalhador como área de competência própria da saúde ${ }^{5}$. Em 2002, por meio da Portaria GM/MS n $1.679^{6}$, foi criada a Rede Nacional de Atenção Integral à Saúde do trabalhador (Renast), considerada como uma grande oportunidade para o avanço da institucionalização e fortalecimento da saúde do trabalhador no âmbito do Sistema Único de Saúde (SUS). A Renast integra a rede de serviços do SUS, voltada à promoção, à assistência e à vigilância para o desenvolvimento de ações de saúde do trabalhador.

Diante da necessidade de informação sobre o perfil dos trabalhadores e a ocorrência de agravos relacionados ao trabalho, para orientar as ações de saúde, foi publicada em 2004 a Portaria GM/MS n ${ }^{\circ}$ $777^{7}$, na qual há a listagem de onze desses agravos, que passa a exigir notificação compulsória por meio do Sistema de Informação de Agravos de Notificação (Sinan), entre os quais as LER/DORT. Assim, desde 2006 os estados registram esses agravos em unidades sentinelas específicas.

As unidades sentinelas compõem a Rede de Serviços Sentinela em Saúde do Trabalhador, que representa uma importante estratégia da Renast para garantir a informação em saúde do trabalhador e viabilizar a vigilância da saúde. A rede sentinela é estruturada por serviços assistenciais de retaguarda, de média e alta complexidade, já instalados no SUS, que proporcionam informações que subsidiarão ações de prevenção, vigilância e intervenções em saúde do trabalhador ${ }^{8}$.

Na perspectiva de consolidação de uma Vigilância em Saúde integrada, a Portaria GM/MS n ${ }^{\circ} 104 / 2011^{9}$ incluiu os agravos à saúde do trabalhador na relação das doenças, agravos e eventos em saúde pública de notificação compulsória no território nacional, além de estabelecer fluxos, atribuições e responsabilidades dos profissionais de saúde e serviços. Essa portaria proporcionou maior visibilidade aos agravos em saúde do trabalhador ao incluí-los na mesma lista dos demais agravos e eventos em saúde pública de notificação no país.

Contudo, apesar de os registros dos agravos relacionados ao trabalho terem iniciado no SUS em 2006, os números referentes às notificações do agravo LER/DORT no Sinan, em todo o país, são ainda reduzidos em comparação aos dados da Previdência Social, que não abrangem a totalidade da população trabalhadora. Os registros do agravo na Previdência Social foram, somente no ano de 2008, 4,9 vezes maiores que o total de notificações no Sinan no período de seis anos, de 2006 a $2011^{10,11}$. De acordo com o Ministério da Previdência Social, as LER/DORT representam as doenças ocupacionais mais frequentes no país ${ }^{12-14}$.

Santana e Silva ${ }^{15}$ apontam que é relevante a subnotificação dos agravos à saúde relacionados ao trabalho nos sistemas de informação do SUS, apesar dos esforços para aumentar gradualmente esses números. Essas autoras afirmam que os registros atuais são pouco expressivos, considerando que representam um pequeno percentual dos registros da Previdência Social, que cobre menos da metade dos trabalhadores do país. 
Dias et al. ${ }^{8}$ destacam que a ausência ou o baixo número de registros dos agravos à saúde relacionados ao trabalho, nos sistemas de informação do SUS, dificultam a visibilidade social dos problemas e sua inserção nas agendas técnica e política dos gestores e conselhos de saúde. Assim, a melhoria desses dados é um desafio assumido nacionalmente para incluir as questões da saúde do trabalhador em todas as instâncias do SUS.

Este artigo tem como objetivo analisar os elementos que influenciam a subnotificação do agravo LER/ DORT no Sinan a partir da percepção dos profissionais que atuam na Rede de Serviços Sentinela em Saúde do Trabalhador na cidade de Palmas (TO).

\section{Método}

Trata-se de pesquisa qualitativa, realizada nas unidades de saúde da Secretaria Municipal de Saúde (Semus) que ofertam serviços especializados na cidade de Palmas (TO) e que são unidades sentinelas para notificação do agravo LER/DORT no Sinan desde 2008.

A seleção das unidades sentinelas para o desenvolvimento da pesquisa foi realizada a partir de informação obtida no setor do Centro de Referência em Saúde do Trabalhador (Cerest) Regional de Palmas responsável pelas notificações dos agravos relacionados ao trabalho, que indicou quais eram as unidades sentinelas responsáveis pela notificação do agravo LER/DORT em maio de 2011, período de elaboração do projeto de pesquisa.

Assim, foram selecionadas todas as unidades sentinelas informadas, compreendendo: Policlínica 303 Norte, Complexo de Atenção à Saúde (CAS) e Centro de Consultas Especializadas de Palmas (Cecep). De acordo com os profissionais do Cerest, as unidades sentinelas notificam os agravos relacionados à saúde do trabalhador de acordo com a especialidade médica oferecida em cada unidade. Em relação ao agravo LER/DORT, as unidades notificadoras são as que possuem ortopedistas em seu quadro de profissionais, sendo que se modificam em virtude de constantes transferências desses especialistas entre as unidades de saúde da Semus.

No total, 25 profissionais de saúde realizavam assistência a pacientes com possíveis diagnósticos de LER/DORT ou eram responsáveis pela notificação dos casos nas unidades de saúde selecionadas. Todos esses profissionais foram convidados para participarem da pesquisa, mas apenas 21 aceitaram. Destes, sete eram médicos ortopedistas (todos os ortopedistas que prestavam atendimentos nessas unidades), quatro enfermeiras, duas técnicas em enfermagem e oito fisioterapeutas.

Os instrumentos para coleta de dados foram entrevistas semiestruturadas individuais. O roteiro de entrevista abordava assuntos como: participação em capacitação sobre LER/DORT e sobre notificação no Sinan; consideração do aspecto ocupação na anamnese dos pacientes para o estabelecimento do diagnóstico; conhecimento para identificar casos de LER/ DORT; conhecimento quanto ao agravo LER/DORT ser de notificação compulsória na unidade de saúde em que trabalhava; conhecimento do fluxo de notificação dos casos identificados; questionamento se havia notificado casos de LER/DORT; importância e finalidade das notificações dos casos de LER/DORT no Sinan; oferecimento de sugestões para melhorar o fluxo de notificação.

Em relação ao termo de consentimento, foram respeitadas as Diretrizes e Normas da Resolução 196/1996 do Conselho Nacional de Saúde ${ }^{16}$. Esta pesquisa foi aprovada pela Comissão de Avaliação de Projetos e Pesquisas da Semus de Palmas e, posteriormente, pelo Comitê de Ética e Pesquisa da Universidade Federal do Tocantins, conforme parecer consubstanciado $\mathrm{n}^{\circ}$ 049/2011.

As entrevistas foram gravadas entre setembro e novembro de 2011, totalizando 21 entrevistados, com duração entre 3 e 21 minutos, sendo a maioria com menos de 13 minutos. Após transcritas, foi realizada a análise de conteúdo, desenvolvida a partir da proposta de $\operatorname{Bardin}^{17}$.

Para proteger a identidade dos participantes, optou-se pelo uso de siglas, sendo: $\mathrm{F}$ - fisioterapeuta, $\mathrm{E}$ - enfermeiro, $\mathrm{M}$ - médico, TE - técnico em enfermagem, seguidas de um número para cada profissional dentro de sua área.

As etapas da análise iniciaram com a pré-análise, na qual se realizou a leitura flutuante das entrevistas, buscando conhecer as mensagens nelas contidas, a partir das impressões, representações e emoções expressas. Em seguida, sucedeu a fase de exploração do material, que contemplou a definição de unidades de registro e de contexto, e a categorização que propiciou a extração das categorias analíticas e subcategorias.

Ressalta-se que foi elaborado um quadro de análise contendo os itens "categorias", "subcategorias", "unidades de registro" e "unidades de contexto", sistematização necessária para facilitar a organização e análise dos dados.

A última fase contemplou o tratamento dos resultados, a inferência e a interpretação, que permitiram a análise reflexiva dos conteúdos extraídos das entrevistas. 


\section{Resultados}

No Tocantins a situação de subnotificação é similar à nacional, tendo em vista que no período de 2007 a 2011 somente 128 casos de LER/DORT foram notificados. Desses, 85 foram notificados em Palmas (TO), porém esse registro acontece em sua maioria no Cerest Regional de Palmas. A notificação do agravo LER/DORT nas unidades sentinelas implantadas em 2008 em Palmas apresenta números muito reduzidos; nas três unidades sentinelas que fizeram parte desse estudo foram notificados somente 13 casos até o ano de 2011.

A seguir, na primeira parte, serão apresentados elementos que dificultam a identificação e notificação das LER/DORT, como desconhecimento quanto à natureza do agravo, aspectos clínicos, epidemiológicos e protocolo; insuficiência de trabalho em equipe; capacitação dos profissionais; indefinição dos papéis de cada profissional na identificação e notificação do agravo LER/DORT; e a desvalorização da identificação e notificação do agravo. Na segunda parte serão abordadas as sugestões de melhorias para aumentar as notificações.

\section{Elementos que dificultam a identificação e notificação do agravo LER/DORT}

\section{Desconhecimento quanto à natureza do agravo, aspectos clínicos, epidemiológicos e protocolo}

Mais da metade dos ortopedistas relatam apresentar dúvidas na identificação das LER/DORT, sendo que um afirma que não sabe identificar casos. Percebe-se que esses profissionais apresentam diferentes explicações para as LER/DORT. Alguns consideram que os números desse agravo não traduzem a realidade, que são bem menores que os divulgados, pois acreditam que doenças de caráter degenerativo estão sendo classificadas como LER/DORT, havendo confusão no estabelecimento do diagnóstico.

Eu acredito que a porcentagem de LER/DORT é infinitamente menor do que a que se apresenta na rotina dos médicos. [...] Está sendo feita uma confusão de diagnóstico entre doenças que sempre existiram que são degenerativas, por exemplo, as bursites, as tendinites e doenças que hoje são catalogadas como ocupacionais. Está havendo uma confusão de diagnóstico muito grande por parte dos profissionais de saúde. (M1)

Até porque na verdade isso tem muitas pesquisas, mas não tem nada fechado até agora. [...] Porque um grupo todo que faz a mesma coisa um tem e o outro não. Provavelmente esse não está capacitado para fazer aquilo que ele quer. Se eu te mandar hoje fazer uma corrida de maratona de $42 \mathrm{~km}$, você vai aguentar? [...] Então eu acho que tem que ver como um todo, o paciente muitas vezes é sedentário, obeso, fumante, hipertenso e ele evolui com uma tendinopa- tia que é normal numa alteração degenerativa e você joga isso como LER/DORT, eu acho que é simplificar muito uma doença que é grave, que não é só aquilo ali. [...] Na verdade é difícil você conseguir classificar, classificar quase todos eu vou falar que é LER/ DORT, isso que eu estou te falando, a gente vai passar do atual cenário de subnotificação para um cenário de epidemia, que nenhum dos dois é a verdade. (M2)

A alegação da simulação por parte dos trabalhadores pôde ser verificada neste estudo: em alguns relatos, os sintomas apresentados pelos pacientes são vistos como fingimentos, com o objetivo de tirarem proveito disso, muitas vezes orientados pelos advogados.

\begin{abstract}
Até que ponto é real, até que ponto são dissimulados os sintomas, essa é a dificuldade, de natureza técnica. [...] O paciente com certeza está fazendo muito uso dessas doenças catalogadas. Ele está querendo se colocar dentro desse quadro de doenças ocupacionais catalogadas. (M1)
\end{abstract}

Para um dos entrevistados, as consequências para o corpo são vistas como inerentes ao trabalho; dessa forma, as doenças sempre ocorreriam e todos os que trabalham teriam DORT. Nesse contexto, não é possível identificar os casos e notificá-los, pois todos os trabalhadores seriam notificados.

Qualquer esforço repetitivo, todos os seres humanos
têm, todos. Então a palavra "lesões por esforços re-
petitivos" pra mim é errônea; a DORT sim é mais
adequada. Então eu acho que não existe, pelo fato
de várias pessoas na sua profissão fazerem esfor-
ços repetitivos, o sentar até é um esforço repetitivo,
então por isso eu não acho que não é adequada a
nominação[...]. Eu acho que todo mundo tem, não
é que não existe. [...] Por exemplo, o paciente tem
tuberculose, se ele trabalhar, ele também tem DORT.
Então todos, eu acho, que tem DORT, você tem DORT,
eu tenho DORT. (M6)

Percebe-se que alguns médicos desconhecem sua obrigação em estabelecer o nexo causal entre os transtornos de saúde e as atividades do trabalhador, apesar de essa obrigação ser descrita na Resolução do CFM n ${ }^{0} 1.488$, de $1998^{18}$, abrangendo todos os médicos que prestam assistência a trabalhadores, independentemente de sua especialidade ou local em que atuem. Como se identifica na fala a seguir:

O objetivo da gente aqui da prefeitura é fazer o aten-
dimento ambulatorial, para essa parte que é direcio-
nada ao trabalho, a parte ocupacional, eu acho que
deveria ser separado porque você atende aqui vinte,
trinta pessoas, às vezes fica difícil você discernir um
caso domiciliar e de um caso do trabalho. [...] É difí-
cil (identificar casos de LER/DORT), se já vem assim
relacionado com a questão do trabalho fica mais fá-
cil pra gente, se viesse já separado [...] aí às vezes
você se confunde, eu estou aqui para ser médico
assistente, eu não sou perito. (M5)

Como acreditam não ser sua função identificar os casos de LER/DORT por não serem peritos, não o 
fazem, principalmente pelo número elevado de atendimentos que realizam.

Observa-se nos relatos dos ortopedistas uma supervalorização dos exames complementares para a identificação do agravo e a impossibilidade em identificar as LER/DORT se justifica pela lentidão em que os exames são realizados. Segundo o M2, "o diagnóstico é clínico e por imagem, e, fora isso, ver essa parte laboral e ergonômica, só o que eu peço hoje demora mais ou menos uns oito meses pro paciente trazer".

Na fala de alguns ortopedistas é possível perceber muitas dúvidas na identificação das LER/DORT e que não se baseiam em nenhum protocolo ou normativas existentes, como também não se utilizam das evidências epidemiológicas que indicam se determinados ramos de atividades e funções são conhecidos como de risco para LER/DORT.

O nosso paciente é difícil, é um paciente que tem muita queixa $[. .$.$] às vezes você tem dificuldade, o$ paciente está com uma LER, você jura que é uma LER/DORT na consulta anterior, quando ele volta na outra ele já esqueceu aquela doença e começou com outra, então isso não é uma LER/DORT, a LER/DORT ela não sara sozinha, ela se mantém [...] eu acredito que a notificação não pode ser feita na primeira consulta e talvez nem na segunda, talvez só na terceira que aí você vai ter um apanhado [...]. Então tem que ter um acompanhamento e até esperar o tratamento, porque às vezes o tratamento não dá certo, aí você considera como uma LER, uma DORT. (M4)

Em relação à identificação das LER/DORT por parte dos outros profissionais da equipe, os que relatam saber identificar o agravo são alguns fisioterapeutas e um enfermeiro. Mas, muitos apresentam dúvidas e dificuldades na identificação.

Evidencia-se, também, nas falas de alguns desses profissionais, o desconhecimento sobre o Protocolo do Ministério da Saúde relacionado a esse agravo e sobre a Lista das Doenças reconhecidas como LER/DORT.

Para F7, "tem certas coisas que eu tenho a impressão que é e pode não ser [...] porque a gente não tem um guia, um manual dizendo assim 'olha, são essas daqui, só essas daqui e ponto final’”.

Por meio dos relatos, verificou-se que somente uma pequena parte dos entrevistados notifica os casos de LER/DORT, sendo esses fisioterapeutas e técnicos em enfermagem. Identificou-se que nenhum médico entrevistado afirmou notificar os casos. Dessa forma, os únicos profissionais que identificam os casos são os fisioterapeutas, que, com a equipe de enfermagem, realizam as notificações.

\section{Insuficiência de trabalho em equipe}

Considera-se que o trabalho em equipe representa um dos pontos centrais na reorganização da atenção à saúde no SUS, sustentada por projetos assistenciais mais integrais e resolutivos, capazes de promover mudanças nos processos de trabalho e nas formas de atuar sobre o processo saúde-doença por meio de uma maior interação entre os profissionais e suas ações ${ }^{19}$.

Contudo, a simples composição de equipes multiprofissionais nos serviços não se configura necessariamente como um trabalho em equipe. Isso pode ser verificado nas unidades estudadas, onde, apesar de serem compostas por profissionais de diferentes formações, não predomina a troca de informações, saberes e discussões entre esses sujeitos.

Aqui, como eu costumo brincar com um colega fisioterapeuta, é um por si, Deus por todos e vamos lá. Você morre de trabalhar e segue em frente, tem que fazer de conta que não está vendo nada e fazer sua parte, o que dá pra você fazer você faz, o que não dá... (F2)

A falta de interação acontece principalmente com os médicos, pois na maior parte das vezes os outros profissionais da equipe não têm contato com os ortopedistas e não há possibilidade de discussão de casos - se necessário, encaminham o caso para consulta em formulário de referência padronizado, que deverá ser agendada pela Semus. Segundo M6, "não [há trabalho em equipe], eu não sei nem onde é que tem fisioterapia, para você ter uma ideia”.

Trabalho em equipe é direcionado, a gente faz aquela fichinha de encaminhamento para o especialista e o paciente tem que procurar a secretaria e ir pra fila de espera até um, dois, três, quatro, seis meses depois para aquele profissional chamar ele [...]. Há uma dificuldade muito grande desse feedback entre um profissional e outro no sentido de se eu acho que é uma LER/DORT. (F4)

Outro fato observado é a supremacia do poder exercido pelo profissional médico, como mostrada na fala de um entrevistado.

Às vezes [o encaminhamento médico para notificação] contém CID, mas raramente, dificilmente. Aí a gente orienta com o fisioterapeuta, normalmente eles já sabem quando o médico não manda o CID. (TE2)

Na ausência de CID no encaminhamento médico para notificação, o profissional que faz o registro tira as dúvidas com o fisioterapeuta e não com quem fez o encaminhamento.

\section{Capacitação dos profissionais}

A maior parte dos entrevistados considera que não foi capacitado para identificar e notificar o agravo e não havia participado de curso ou qualificação sobre LER/DORT em sua carreira (dos cursos que participaram, nenhum deles foi ofertado pela Semus de Palmas). Uma minoria havia participado de capacitações sobre notificação dos agravos relacionados à saúde do trabalhador no Sinan. Apesar 
de as unidades sentinelas terem sido implantadas em 2008, alguns tiveram conhecimento de que a unidade em que trabalhava notificava LER/DORT somente poucos meses antes da entrevista.

Eu creio que faltou também, assim, uma participação maior dos próprios funcionários do Cerest em relação à gente, de tá mostrando, de tá convidando né pra cursos, capacitações, porque assim, uma coisa que até eu queria falar, a gente viu aquele banner de unidade sentinela. Eu olhava pra aquilo lá e eu pensei "nossa, mas não foi passado nada pra gente", tá ali aquele banner que a gente faz a notificação de LER/ DORT, mas eu não sabia nem por onde começar. (F8)

Teve o pessoal do Cerest que foi lá com a gente, mostrou a ficha, eles só mostraram a ficha e explicaram como preenche e no caso passou pra gente uma listinha lá de quais são os CID [...] não sei se isso é considerado capacitação. (F3)

Não foi bem uma capacitação, elas vieram e passaram algumas instruções de como seria o preenchimento da notificação e aí junto comigo estava o médico do dia, mas as informações mesmo que passaram foram só essas, o modo que ia preencher e como eu ia poder identificar esses pacientes, porque eu só teria como identificar através do atendimento deles, através do atendimento do médico [...] às vezes pode ser que passe um paciente por mim que tenha LER/DORT e eu não sei identificar justamente porque eu não tive capacitação e ainda não tenho conhecimento. (E2)

Acredita-se que a estratégia de qualificação dos profissionais adotada pelo Cerest, em virtude da organização do processo de trabalho dentro dessas unidades, não supriu as necessidades da equipe. Percebe-se que os técnicos do Cerest consideram que os profissionais que prestam assistência aos trabalhadores já possuem conhecimento sobre as LER/DORT, em razão de suas formações, portanto, a explicação sobre a ficha de notificação e lista com as doenças seriam suficientes, mas isso não foi verificado nos relatos dos profissionais.

Um fato que mostra a fragilidade da estratégia de qualificação dos profissionais, diz respeito a menos da metade ter conhecimento de que o agravo LER/ DORT é de notificação compulsória nas unidades em que trabalham, apesar de alguns já terem sido orientados pelos técnicos do Cerest.

Outro ponto que merece destaque em relação ao processo de qualificação é a forma de abordagem dos profissionais para as orientações. De acordo com o exposto, foram realizadas individualmente ou em grupo por categoria profissional.

Foi em uma salinha separada junto com todas as técnicas, não só eu, com todas as técnicas que estavam presentes [...] não reuniu todo mundo devido ao horário de trabalho aqui, aí tem que pegar o horário que o funcionário está à disposição. (TE2)
Indefinição dos papéis de cada profissional na identificação e notificação do agravo LER/DORT

A indefinição dos papéis dos profissionais na identificação e notificação dos casos de LER/DORT gera mais dúvidas aos fisioterapeutas. No Protocolo de LER/DORT do Ministério da Saúde, do ano de 2006, que ficou em versão preliminar e foi publicado em $2012^{20}$, com o nome de Dor Relacionada ao Trabalho/Lesões por esforços repetitivos/Distúrbios osteomusculares relacionados ao trabalho, ressalta-se que: "a etapa do estabelecimento da relação de causa e/ou agravamento entre o trabalho e o quadro clínico é atribuição multidisciplinar; pressupõe-se a técnica de realizar uma boa anamnese ocupacional, que não é atribuição exclusivamente médica" ${ }^{20}$.

Apesar dessa afirmação, não fica evidente como os outros profissionais poderiam fazer esse nexo causal com o trabalho, se para o estabelecimento seria obrigatoriamente necessário partir de um diagnóstico médico das doenças previamente estabelecido e se o profissional não médico poderia aplicar a classificação da CID correspondente e concomitantemente estabelecer o nexo. Esse problema se agrava pelo fato de não existir trabalho em equipe nas unidades estudadas.

Percebe-se que essa falta de clareza dos papéis dos profissionais, sobretudo da fisioterapia, causa dúvidas aos técnicos do Cerest, que, consequentemente, orientam de formas diferentes esses profissionais. Em uma das unidades, mais ou menos dois anos antes de serem entrevistados, os fisioterapeutas foram orientados a fazer, com técnicos do Cerest, uma busca ativa nos prontuários da fisioterapia, com o objetivo de identificarem casos de LER/DORT nos usuários que estavam em atendimento ou haviam sido atendidos no setor.

Já na outra unidade, segundo os relatos, somente poucos meses antes das entrevistas, os profissionais foram orientados a notificar. Nos casos em que não estivesse estabelecido diagnóstico médico e CID da doença, era para encaminhar novamente para o médico defini-lo.

Teve uma vez que a profissional do Cerest veio aqui, passou pra gente encaminhar, mas falou pra gente conversar com o médico também [...] mas aí é uma briga danada, o cara fala que não existe e como é que vai forçar porque tem que ter, segundo ela, tem que ter naquela fichinha de notificação o diagnóstico clínico e tem que ter o CID da LER/DORT. Mas se colocou muito como um dever do médico e aquele campo só pode ser preenchido pelo médico e tal [...] como o diagnóstico clínico é de responsabilidade do clínico a gente fica meio de mãos atadas, né? Até de certa forma com medo pra te falar a verdade, eu fiquei meio receoso em fazer, direcionar alguns pacientes. (F4) 
Assim, a indefinição nos papéis de cada profissional provoca dúvida, medo e insegurança, havendo muito receio dos demais profissionais em invadir as funções específicas dos médicos.

\section{Desvalorização da identificação e notificação do agravo LER/DORT}

A maior parte dos entrevistados considera importante a notificação dos casos no Sinan devido aos seguintes aspectos: identificação dos casos; prevenção das lesões; melhor sequência do tratamento e acompanhamento do paciente; conhecimento do quantitativo para entrar com medidas de prevenção, planejamento de ações e formulação de políticas públicas na área; notificação de empresas que estão causando o agravo; possibilitar a realização de capacitações nas empresas; intervenção nos casos; por ser um agravo sequelante.

Entretanto, mesmo sendo relevante para a maioria dos profissionais, percebe-se que a maior parte dos ortopedistas desvaloriza a identificação e a notificação do agravo por diversas razões.

Um entrevistado relata que identificar as LER/ DORT não modifica a conduta e o tratamento do usuário, por isso não há preocupação em classificar as doenças como LER/DORT. Além disso, a notificação de doenças do trabalho ainda não tem relevância diante da inexistência atual de prevenção das doenças básicas.

Nem sempre há preocupação de fazer esse diagnóstico também [...] na minha função, o fato de ser LER/ DORT ou não, não muda nada a conduta do tratamento. Se tiver que afastar do trabalho eu afasto, se tiver que mudar eu mudo, mas não por uma questão de classificação ou de qualquer outra coisa. [...] Mas não sei se funciona [notificação das LER/DORT no Sinan]. (M7)

É possível perceber o desconhecimento de outro entrevistado quanto à finalidade dos dados do Sinan quando afirma que devem focar os esforços no incentivo e estímulo ao trabalhador do SUS e não em notificações, pois acredita que os sintomas apresentados pelos trabalhadores podem ser encontrados em qualquer pessoa, de qualquer faixa etária, mesmo que não trabalhe.

O funcionário tem que ser mais incentivado, o funcionário tem que ser melhor remunerado, o funcionário tem que ter estímulo para o trabalho e essa é a preocupação principal, nem tanto ficar notificando coisas que às vezes não são reais. Até porque as dores que frequentemente são relacionadas aos acidentes de trabalho, às doenças ocupacionais, essas dores elas existem na população que não trabalha inclusive, ou que já passou da idade de trabalhar, ou que ainda não tem idade para trabalhar e nessas situações não são notificadas como doença ocupacional [...]. Acho que o Ministério está muito interessado em diagnos- ticar doenças ocupacionais e pouco interessado em estimular o trabalhador com qualificação, com cursos de qualificação técnica, com incentivos salariais, ele está muito mais interessado em notificar e eu não entendo isso. (M1)

Para outro entrevistado, a notificação das LER/ DORT no Sinan está banalizando o agravo, pois considera que só se pode notificar após identificação que está vinculada à eliminação de todos os fatores predisponentes (obesidade, fumo, hipertensão, sedentarismo).

\begin{abstract}
Não é que não é importante [notificação no Sinan], nos moldes que hoje é eu não acredito [...] eu acho que hoje o objetivo é querer banalizar a coisa, eu acho que precisa estudar mais, eu acredito muito no pessoal da USP, no trabalho que eles fizeram que mostrou isso, então quer dizer, se você conseguir zerar todos os fatores [predisponentes]. (M2)
\end{abstract}

Em outro relato, o entrevistado considera importante a notificação no Sinan, mas compactua com a ideia que hoje há banalização dos casos, muitos estão sendo erroneamente identificados.

É [importante notificação no Sinan], mas eu acredito que se banalizou demais os casos de LER e DORT, foi o que eu falei, qualquer doença apenas o relato do paciente com observação de um colega, do médico e já considera uma LER e não é [...]. Então, assim, eu acho que tem muito caso, tem, mas tem muito caso que não é. (M4)

Destaca-se em outras falas que a notificação no Sinan não interferirá positivamente no acesso do usuário ao tratamento. Um dos entrevistados acredita que a notificação no Sinan não é relevante porque o paciente não consegue realizar o tratamento na rede: "aí vamos ver [...] o tratamento é fisioterápico, é medicamentoso, ele não consegue, então, na verdade, notificar por notificar se a gente não consegue" (M2).

Pelo exposto, evidencia-se que, diante das diferentes explicações para a ocorrência das LER/ DORT, torna-se irrelevante para a maior parte dos ortopedistas identificar o agravo e, consequentemente, não há também importância na notificação no Sinan, partindo-se do pressuposto que possuem variados entendimentos quanto à finalidade do banco de dados.

\section{Sugestões de melhoria}

Alguns relatos mostram que há muita vontade por parte dos profissionais de que haja uma maior interação entre eles e que seja encontrada uma forma de trabalharem em equipe multidisciplinar, o que facilitaria as notificações.

Extremamente importante eu acho que é a interação da equipe multidisciplinar, sabe, de você estar reunindo mais os profissionais [...] eu creio que, se 
o médico participar também da equipe, com certeza as notificações elas terão um avanço melhor [...]. Eu creio, assim, que reuniões, reuniões mensais ou quinzenais, que fossem encontrados realmente os profissionais para estar discutindo isso. (F8)

Uma das propostas apresentadas pelo grupo foi a organização de reuniões periódicas com a equipe.

Outro aspecto evidenciado foi a necessidade de uma articulação e interação mais fortalecida com o Cerest, que tem como uma das funções proporcionar suporte técnico especializado para a rede de serviços do SUS.

Eu acho que seria essa interação entre médico, fisioterapeuta e Cerest. Seria uma interação entre esses três atores pra padronizar a forma de notificação e o próprio contato entre a gente e os médicos, pra no caso de ter uma falha, caso haja alguma falha em relação a colocar CID ou no fechar um diagnóstico, pra gente ter esse acesso mais rápido pra poder fazer essa notificação. (F6)

Apesar da necessidade de maior articulação entre os profissionais, verificada nos relatos da equipe, não se conseguiu visualizar iniciativas para transformar essa realidade.

\section{Discussão}

O discurso dos entrevistados médicos que afirmam que os números de casos de LER/DORT são bem menores que os divulgados, não condizem com os dados publicados referentes à ocorrência de LER/DORT. Estima-se que a proporção de todas as doenças musculoesqueléticas da população mundial que são atribuíveis ao trabalho é cerca de $30 \%{ }^{2}$. Acredita-se que esse agravo represente, atualmente, a maior categoria de doença relacionada ao trabalho na Grã-Bretanha. O Health and Safety Executive (HSE) estima que em 2004/2005 as LER/DORT afetaram um milhão de pessoas, gerando alto custo para a sociedade $^{21}$. No Brasil, as estatísticas da Previdência Social mostram que os benefícios acidentários por incapacidade concedidos para afecções musculoesqueléticas foram 117.353 em 2008, 98.415 em 2009 e 88.270 em $2010^{22}$.

Em alguns relatos foram citadas doenças degenerativas que estão erroneamente classificadas como LER/DORT, porém essas doenças constam na Lista de Doenças Relacionadas ao Trabalho do Ministério da Saúde e Previdência Social e podem ser enquadradas como LER/DORT se tiverem relação como o trabalho.

A tendência de negação das LER/DORT como doenças do trabalho foi encontrada por Verthein ${ }^{23}$, em pesquisa realizada com a perícia médica do INSS, em que mais de $80 \%$ das LER identificadas por outros médicos foram registradas como doenças crônico-degenerativas, que podem acometer as pessoas em geral, negando o nexo do processo de adoecimento com o trabalho, afirmando o quadro como predisposição do sujeito. A doença era vista como subjetiva, e os trabalhadores eram considerados como simuladores, fingindo estar doentes para não trabalhar.

Martin e Bammer ${ }^{24}$ afirmam que a explicação para as LER/DORT na qual os trabalhadores são vistos como simuladores de dor e de incapacidade para evitar o trabalho ou obter uma indenização beneficiam principalmente empregadores e seguradoras. Maeno $^{22}$ acrescenta que não há na literatura estudos consistentes que confirmem o posicionamento dos que afirmam que as origens das LER/DORT se encontram no campo da psiquiatria ou na má intencionalidade e não nas condições de trabalho. A autora destaca que cursos e eventos para peritos têm se pautado em como identificar simulações nos exames médicos periciais, o que não contribui para a efetiva formação dos peritos no diagnóstico das doenças relacionadas com o trabalho. É provável que a maior fragilidade na formação dos peritos esteja na capacidade de investigar com acurácia a exposição ocupacional aos fatores de risco para as LER/DORT. Identificar o simulador não capacitará, por certo, o perito para o diagnóstico diferencial entre o que é ou não relacionado com o trabalho. E esta deve ser sua principal ferramenta de investigação.

A visão que afirma ser função do perito estabelecer as LER/DORT é encontrada no estudo de Sakata et al. ${ }^{25}$, que indica que há necessidade de médico perito do INSS reconhecer que a lesão foi causada pelo trabalho e para tanto haveria necessidade do perito conhecer o local de trabalho, o que geralmente não ocorre. Então, a informação seria dada pelo médico do trabalho da empresa. Diante desse posicionamento, pode-se perceber que todos os que não são amparados pelo INSS, mais de 50\% da população trabalhadora, ficariam sem o estabelecimento do nexo causal entre as patologias e o trabalho.

Segundo alguns autores, o diagnóstico das LER/ DORT é essencialmente baseado no histórico ocupacional e exame clínico e, dessa forma, para a maioria dos pacientes com LER/DORT, não há necessidade de exames complementares e quando realizados podem ser normais ${ }^{26,27}$.

O Ministério da Saúde enfatiza que os exames complementares, quando indicados corretamente, podem auxiliar no diagnóstico clínico, porém não no estabelecimento da relação do quadro clínico com o trabalho, que depende da avaliação da exposição ocupacional ${ }^{26}$.

Concorda-se com Verthein e Minayo-Gomez ${ }^{28}$ quando ressaltam que o fator que realmente importa 
para a abordagem que supervaloriza os exames complementares não é o que o médico absorve na escuta ou percebe no exame físico, mas a imagem que obtém da tecnologia sofisticada. Assim, "os médicos fazem a leitura do corpo a partir da transparência dele, ou seja, interpretam seus sentidos pelas imagens que representam os fatores de adoecimento" ${ }^{28}$.

Nesse sentido, pelo fato de as LER/DORT serem um agravo cuja etiologia é multicausal, torna-se difícil o diagnóstico, de acordo com os parâmetros médicos, quando se busca apenas uma etiologia, o que gera dúvidas e incertezas. Somam-se a isso dúvidas relativas à sintomatologia, uma vez que os exames não evidenciam a doença em seu estágio inicial. No entanto, para o diagnóstico cabe a investigação do papel do trabalho na ocorrência do agravo, ou seja, a pergunta norteadora deve ser se há ou não exposição ocupacional, se há ou não, portanto, condições de trabalho que contribuíram para o agravo, habitualmente de origem multicausal.

Boa parte dos ortopedistas participantes deste estudo apresenta diferentes explicações para as LER/DORT (sem fundamentação científica), não possui clareza conceitual sobre o agravo, e desconhece as estatísticas disponíveis e a relevância desse agravo para a saúde pública. Muitas das explicações apresentadas beneficiam principalmente as empresas e a previdência social. Salienta-se que a legislação trabalhista garante ao trabalhador regido pela CLT (Consolidação das Leis do Trabalho), entre outros direitos, o recebimento de complementação salarial, quando é acometido por doenças do trabalho. Evidenciou-se nesta pesquisa a falta de interesse por parte dos médicos em estabelecer o nexo causal, consequentemente, restringindo os direitos dos trabalhadores.

$\mathrm{Na}$ fala de alguns entrevistados, foi possível perceber a consciência de que a falta de trabalho em equipe prejudica o trabalho e a desresponsabilização pelo usuário em decorrência da insuficiência do trabalho individual. A Política Nacional de Humanização da Atenção e Gestão do SUS (PNH) problematiza que a divisão do trabalho em saúde, em que predomina a responsabilidade parcial sobre procedimentos, diagnósticos e parte dos corpos das pessoas, confirma a fragmentação do processo de trabalho e produz uma progressiva redução do objeto de trabalho, a individualização e a desresponsabilização do trabalho, da atenção e do cuidado ${ }^{29}$.

Segundo Cardoso e Hennington ${ }^{30}$, o modelo predominante de organização das práticas de atenção à saúde é o modelo clínico de assistência médica individualizada ou modelo médico, centrado no saber biomédico e no diagnóstico e tratamento das doenças e sintomas orgânicos. Assim, essas autoras afirmam que as demais áreas reproduzem também esse modelo de atenção e permanecem periféricas em relação ao trabalho médico, considerado o norteador. O modelo de assistência à saúde exposto foi o encontrado nas unidades estudadas, destacando a postura de cada profissional que se responsabiliza pelo atendimento prestado individualmente, centrado na doença.

Compreende-se que a forma como os ortopedistas estão inseridos nas unidades estudadas, nas quais permanecem somente durante poucas horas, normalmente em um único dia da semana, com um número elevado de pacientes agendados, desfavorece a articulação com outros profissionais e o trabalho em equipe. Diante disso, é preciso que a gestão da Semus analise e intervenha nas dificuldades apresentadas, uma vez que é a responsável pelo credenciamento desses profissionais e distribuição do agendamento dos pacientes.

Para que haja um atendimento integral do trabalhador que favoreça a identificação e notificação dos casos de LER/DORT, faz-se necessário repensar o modelo de atenção vigente nessas unidades estudadas. Uma articulação de todos os profissionais com suas especificidades deve visar ações resolutivas e com respostas conjuntas para cada situação.

Alguns autores ressaltam que há em todo o país um desconhecimento expressivo dos agentes de risco e agravos à saúde relacionados com o trabalho por parte dos diversos profissionais da saúde ${ }^{15,31,32}$, sendo considerado um grande desafio fazer cumprir a lei e inserir as ações de saúde do trabalhador no SUS. Esse despreparo dos profissionais de saúde quanto às questões relacionadas à saúde dos trabalhadores se deve à ausência da temática nos cursos de graduação e/ou nos processos de educação permanente em saúde ${ }^{8}$.

Os relatos dos entrevistados expõem a dificuldade de articulação dos profissionais e a fragmentação das ações nas unidades. Compreende-se que o momento de qualificação profissional poderia ser oportuno para o fomento do trabalho em equipe que favorecesse a identificação e notificação das LER/DORT.

Joazeiro e Scherer ${ }^{33}$ ressaltam a riqueza dos diferentes saberes e a potência que se cria ao consolidarmos um modelo de atenção e de formação que seja capaz de agregar a valorização do saber de cada profissão e seja potencializado mediante dispositivos que instituam coletivos de trabalho que se baseiem em um diálogo democrático.

No que diz respeito às dúvidas referentes ao papel dos profissionais da equipe multiprofissional na identificação e notificação das LER/DORT, 
entende-se que, para elucidar esse fato, seja interessante articular e trocar informações com os autores responsáveis pelo Protocolo do Ministério da Saúde. Diante desses subsídios, torna-se mais fácil construir coletivamente, com cada equipe das unidades, o papel de cada um nesse processo.

Diante dos diferentes entendimentos quanto à finalidade da notificação do agravo LER/DORT, surge a necessidade de propiciar nas unidades estudadas discussões sobre a importância da notificação no Sinan, as diretrizes da Política Nacional da Saúde do Trabalhador e da Trabalhadora (PNSTT) ${ }^{34}$, além de contextualizar o papel do Cerest nesse cenário. A maior parte dos profissionais da Semus/Palmas desconhece o papel do Cerest de Palmas, principalmente em relação às ações de vigilância em saúde do trabalhador. Muitos acreditam que o principal objetivo do Cerest é prestar assistência a trabalhadores, pois o Centro foi caracterizado como porta de entrada para trabalhadores nos primeiros anos de sua existência.

É importante salientar que, segundo as diretrizes da PNSTT, as ações em saúde do trabalhador devem ser desenvolvidas de forma descentralizada e hierarquizada, em todos os níveis de atenção do SUS, incluindo as de promoção, preventivas, curativas e de reabilitação ${ }^{34}$. Para isso, torna-se fundamental a formação dos profissionais para o trabalho no SUS.

Além das necessidades expostas, ressalta-se a importância do estabelecimento do fluxo de atendimento integral do trabalhador com LER/DORT no município, abrangendo fluxo de referência e contrarreferência para cada linha de cuidado.

Os participantes deste estudo sugerem o trabalho em equipe como importante fator para aumentar notificações, e como ferramenta as reuniões de equipe. Segundo Abuhab e colaboradores ${ }^{35}$, reuniões de equipe fazem parte do processo de trabalho em saúde e permitem a troca de informações e vivências do cotidiano, propiciando um processo participativo e de compartilhamento de saberes. Esse espaço de discussão pode ser tanto um local para a prática de troca e decisão compartilhada, como também pode ser estabelecido de forma a reforçar o modelo biomédico hegemônico, no qual prevalecem a falta de discussões e a imposição de papéis.

Em consonância com o modelo de atenção que vigora nas unidades estudadas, percebeu-se que os profissionais ainda não se sentiam capazes de provocar mudanças em seus locais de trabalho, persistindo uma postura de espera pela atitude do outro, tornando visível a gestão que faziam de seu próprio trabalho.

Nesse contexto, existe a necessidade de fomentar o protagonismo desses sujeitos para que busquem um trabalho articulado que favoreça a construção de um novo modelo de atenção à saúde, em que os diferentes saberes e experiências sejam valorizados.

As autoras Cardoso e Hennington ${ }^{30}$ afirmam que essa transformação requer "um processo de experimentação e aprendizagem para a formulação de propostas inovadoras de organização e funcionamento das reuniões multiprofissionais ou de outras iniciativas na construção de coletivos e redes".

Santos Filho e Barros ${ }^{36}$ ressaltam que a PNH propõe o apoio institucional como estratégia de abordagem do processo de trabalho em saúde, utilizando esse recurso para ajudar as equipes a analisarem o trabalho em conjunto com os trabalhadores e não fazer por eles. Constitui como estratégia-intervenção para promover mudanças no SUS, fortalecendo os coletivos nos modos de pensar sua inserção no trabalho, qualificando sua capacidade de análise e intervenção.

\section{Considerações finais}

Os resultados encontrados neste estudo evidenciam que diversos aspectos estão relacionados à subnotificação das LER/DORT no Sinan em Palmas, no Tocantins. Entre os mais relevantes, citam-se as dúvidas apresentadas pelos profissionais na identificação do agravo, as indefinições e desconhecimento do papel de cada profissional na identificação e notificação do agravo, a insuficiência do trabalho em equipe e a desvalorização da notificação por parte de alguns profissionais, associada ao desconhecimento da finalidade desses dados.

A subnotificação das LER/DORT ocorre, principalmente, porque os médicos não identificam nem notificam os casos. Compreende-se que a forma como esses profissionais estão inseridos nas unidades sentinelas estudadas, nas quais permanecem durante poucas horas por semana, atendem um número elevado de pacientes e recebem pela quantidade de atendimentos realizados, desfavorece a articulação com os outros profissionais e o trabalho em equipe, interferindo diretamente na identificação do agravo LER/DORT.

O discurso de alguns profissionais, de negação da relação das doenças com o trabalho, apoia-se no modelo de saúde ofertado nas unidades, que sofre influência do setor privado. Outros aspectos, como a formação desses profissionais para atuarem na rede privada, podem interferir na importância dispensada às questões de saúde pública. Acrescenta-se que não há monitoramento contínuo quanto à exigência das notificações nas unidades. 
Verificou-se que muitos profissionais, quando questionados, conseguem identificar casos de LER/ DORT na população atendida, mas ainda não fazem habitualmente o nexo causal entre as doenças e o trabalho, por não incorporarem as questões relacionadas à saúde dos trabalhadores em suas práticas cotidianas de trabalho. Nesse contexto, acredita-se que o desconhecimento do trabalho como importante determinante do processo saúde/doença e da relevância dos agravos à saúde relacionados ao trabalho favoreça a falta de priorização da identificação e notificação dos agravos por parte dos profissionais da saúde.

Evidenciou-se a falta de qualificação dos profissionais das unidades sentinelas quanto à identificação, notificação das LER/DORT e o desconhecimento do Protocolo do Ministério da Saúde para esse agravo. Entende-se que não há uma política de Saúde do Trabalhador estadual e municipal que desenvolva ações efetivas para a implantação do protocolo de diagnóstico e tratamento do agravo, bem como o estabelecimento de fluxos de referência e contrarreferência, e o planejamento de ações de prevenção e promoção da saúde.

Portanto, torna-se fundamental uma maior aproximação do Cerest com as unidades sentinelas de sua área de abrangência, com vistas a exercer o apoio matricial para o desenvolvimento de ações de saúde do trabalhador nos serviços, ofertando ações de educação permanente.

Além disso, é preciso formular estratégias para superar o grande desafio de provocar mudança na organização do trabalho das unidades, para que contemplem a alta complexidade de saberes, a responsabilidade coletiva pelas ações e a efetiva interação dos profissionais. Para isso, é essencial a construção de espaços coletivos nessas unidades e a qualificação dos profissionais em um processo de formação continuada de modo a fomentar o trabalho em equipe e que incorpore tanto discussões sobre as LER/DORT, como a importância da notificação no banco de dados do SUS.

A falta do estabelecimento do nexo causal entre as doenças osteomusculares e o trabalho, além de interferir nos dados do Sinan, que são utilizados para diversos fins, entre os quais subsidiar ações de prevenção, promoção e vigilância da saúde do trabalhador, nega também os direitos dos trabalhadores, conquistados arduamente ao longo dos anos.

Como se sabe, as LER/DORT vêm aumentando a partir das transformações no mundo do trabalho, sobretudo com a reestruturação produtiva ocorrida nas últimas décadas e as novas formas de organização do trabalho, em que predomina o trabalho terceirizado, temporário e precário. Dessa maneira, são de grande relevância os dados provenientes do SUS para proporcionar visibilidade a esse agravo e subsidiar o planejamento de ações para a população brasileira.

Acredita-se, então, que os dados revelados neste estudo trazem subsídios para o desenvolvimento de ações e adoção de estratégias no sentido de contribuir para solucionar a problemática da subnotificação das LER/DORT. Outros estudos devem aprofundar a discussão sobre esse tema relevante para a saúde pública.

\section{Contribuições de autoria}

Ambas as autoras contribuíram igualmente na realização deste trabalho.

\section{Referências}

1. Neves RF, Nunes MO. Incapacidade, cotidiano e subjetividade: a narrativa de trabalhadores com LER/DORT. Interface - Comunicação, Saúde, Educação. 2009;13(30):55-66.

2. Riihimäki H, Viikari-Juntura E. Musculoskeletal System. In: Stellman JM, organizador. Encyclopaedia of Occupational Health and Safety. Geneva: International Labor Organization; 2011 [Citado em 2015 jun 3]. Disponível em: http:// www.ilo.org/iloenc/part-i/musculoskeletal-system/ item/271-overview.

3. Souza NSS, Santana VS. Incidência cumulativa anual de doenças musculoesqueléticas incapacitantes relacionadas ao trabalho em uma área urbana do Brasil. Cad saúde pública. 2011;27(11):2124-34.

4. Scopel J, Oliveira PAB, Wehrmeister FC. LER/ DORT na terceira década da reestruturação bancária: novos fatores associados? Rev saúde pública. 2012;46(5).

5. Brasil. Constituição (1988). Constituição da República Federativa do Brasil. Brasília, DF: Senado Federal; 1988 [Citado em 2011 mar 15]. Disponível em: http://www.planalto.gov.br/ ccivil_03/Constituicao/Constituicao.htm

6. Brasil. Portaria n. ${ }^{\circ} 1.679 / G M$, de 19 de setembro de 2002. Dispõe sobre a estruturação da rede nacional de atenção integral à saúde do trabalhador no SUS e dá outras providências. Diário Oficial da União, 
Brasília, DF, 20 set. 2002;(183):53-6 [Citado em 2011 fev 1]. Disponível em: h http://www.cerest.piracicaba. sp.gov.br/site/images/PORTARIA_1679_RENAST.pdf

7. Brasil. Portaria n. ${ }^{\circ} 777 / \mathrm{GM}$, de 28 de abril de 2004. Dispõe sobre os procedimentos técnicos para a notificação compulsória de agravos à saúde do trabalhador na rede de serviços sentinela específica, no Sistema Único de Saúde - SUS. Diário Oficial da União, Brasília, DF, 29 abril 2004;(81):37-8.

8. Dias EC, et al. Desenvolvimento de ações de saúde do trabalhador no SUS: a estratégia da Rede Nacional de Atenção Integral à Saúde do Trabalhador (Renast). In: Gomez CM, Machado JMH, Pena PGL, organizadores. Saúde do Trabalhador na Sociedade Contemporânea Brasileira. Rio de Janeiro: Fiocruz; 2011. 540 p.

9. Brasil. Portaria n. ${ }^{\circ}$ 104/GM, de 25 de janeiro de 2011. Define as terminologias adotadas em legislação nacional, conforme o disposto no Regulamento Sanitário Internacional 2005 (RSI 2005), a relação de doenças, agravos e eventos em saúde pública de notificação compulsória em todo o território nacional e estabelece fluxo, critérios, responsabilidades e atribuições aos profissionais e serviços de saúde. Diário Oficial da União, Brasília, DF, 26 jan. 2011;(18):37-8 [Citado em 2011 mar 10]. Disponível em: http://bvsms.saude.gov.br/bvs/ saudelegis/gm/2011/prt0104_25_01_2011.html

10. Brasil. Secretaria de Vigilância em Saúde Painel de informações em saúde ambiental e saúde do trabalhador (PISAST); 2012 [Citado em 2012 mar 21]. Disponível em: http://189.28.128.179:8080/ pisast/saude-do-trabalhador/apresentacao/lerdort/28-fevereiro-dia-internacional-de-prevencaodas-ler-dort

11. Todeschini R, Lino D, Melo LEA. O Ministério da Previdência Social e a institucionalidade no Campo da Saúde do Trabalhador. In: Chagas AMR, Salim CA, Servo LMS, organizadores. Saúde e Segurança no Trabalho no Brasil: aspectos institucionais, sistemas de informação e indicadores. Brasília, DF: Ipea; 2011. 396 p.

12. Brasil. Empresa de Tecnologia e Informações da Previdência Social. Anuário Estatístico da Previdência Social. Acidentes de trabalho registrados segundo CID; 2010 [Citado em 2012 abr 2]. Disponível em: http://www.mpas.gov.br

13. Brasil. Empresa de Tecnologia e Informações da Previdência Social. Anuário Estatístico da Previdência Social. Acidentes de trabalho registrados segundo CID; 2011 [Citado em 2013 nov 1]. Disponível em: http://www.mpas.gov.br

14. Brasil. Empresa de Tecnologia e Informações da Previdência Social. Anuário Estatístico da Previdência Social. Acidentes de trabalho registrados segundo CID; 2012 [Citado em 2012 maio 10]. Disponível em: http://www.mpas.gov.br

15. Santana VS, Silva JM. Os 20 anos da saúde do trabalhador no Sistema Único de Saúde do Brasil: limites, avanços e desafios. In: Brasil. Ministério da Saúde. Secretaria de Vigilância em Saúde. Departamento de Análises de Situação de Saúde. Saúde Brasil 2008. Saúde Brasil 2008: 20 anos do Sistema Único de Saúde (SUS) no Brasil. Brasília, DF: Ministério da Saúde; 2009. p. 175-204.

16. Brasil. Ministério da Saúde. Conselho Nacional de Saúde. Diretrizes e Normas Regulamentadoras de Pesquisas Envolvendo Seres Humanos. Resolução 196/96. Brasília, DF, 1996 [Citado em 2010 abr 20]. Disponível em: www.datasus.gov.br/conselho/ resol96/RES19696.htm

17. Bardin L. Análise de Conteúdo. Lisboa: Persona; 1977.

18. Conselho Federal de Medicina. Resolução CFM n ${ }^{\circ}$ 1.488/1998. Diário Oficial da União, Brasília, DF, de 06 de março de 1998, Seção I, p. 150 [Citado em 2011 maio 12]. Disponível em: http://www.diesat. org.br/arquivos/2306/RESOLUCAO_1488_98.pdf

19. Costa RKS, Enders BC, Menezes RMP. Trabalho em equipe de saúde: uma análise contextual. Ciênc Cuid Saúde. 2008;7(4)530-6 [Citado em 2011 maio 6]. Disponível em: http://repositorio. ufrn.br:8080/jspui/bitstream/1/3102/1/2008ART Trabalhoemequipe_BerthaCruzEnders.pdf

20. Brasil. Ministério da Saúde. Secretaria de Vigilância em Saúde. Departamento de Vigilância em Saúde Ambiental e Saúde do Trabalhador. Dor relacionada ao trabalho: lesões por esforços repetitivos (LER): distúrbios osteomusculares relacionados ao trabalho (Dort). Brasília, DF: Ministério da Saúde; 2012. 68 p.

21. Cooper C, Palmer K. Repeated movements and repeated trauma affecting the musculoskeletal system. In: Baxter PJ, et al. Hunter's diseases occupations. 10 ed. Londres: Hooder Arnold; 2010.

22. Maeno M. LER e transtornos psíquicos relacionados ao trabalho: faces de uma mesma moeda. In: Sznelwar LI, organizador. Saúde dos Bancários. 1ed. São Paulo: Publisher Brasil: Gráfica Atitude; 2011. p. 207-230.

23. Verthein MAR. Jogos de poder instituindo saber sobre as Lesões por Esforços Repetitivos: as redes discursivas da recusa do nexo [thesis]. Rio de Janeiro: Fundação Oswaldo Cruz; 2001.

24. Martin B, Bammer G. When experts disagree. In: Don Ranney MD, organizador. Chronic musculoskeletal injuries in the workplace. Filadélfia: W. B. Saunders Company; 1997. p. 101-113.

25. Sakata RK, et al. Lesão por esforço repetitivo (LER) Doença osteomuscular relacionada ao trabalho (DORT). Rev bras med. 2003;60.

26. Brasil. Secretaria de Políticas de Saúde. Protocolo de Investigação, Diagnóstico, Tratamento e Prevenção de Lesão por Esforços Repetitivos /Distúrbios Osteomusculares Relacionados ao Trabalho. Brasília, DF: Ministério da Saúde; 2000. 31 p.

27. Chiavegato Filho LG, Pereira JRA. LER/ DORT: multifatorialidade etiológica e modelos explicativos. Interface - Comunicação, Saúde, Educação. 2004;8(14):149-62. 
28. Verthein MAR, Gomez CM. O território da doença relacionada ao trabalho: o corpo e a medicina nas LER. Physis: Revista de Saúde Coletiva. 2000;10(2):101-127.

29. Brasil. Secretaria de Atenção à Saúde. Política Nacional de Humanização da Atenção e Gestão do SUS. Clínica ampliada e compartilhada. Brasília, DF: Ministério da Saúde; 2009.

30. Cardoso CG, Hennington EA. Trabalho em equipe e reuniões multiprofissionais de saúde: uma construção à espera pelos sujeitos de mudança. Trab educ saúde. 2011;9(Suppl. 1):85-112.

31. Dias EC, Hoefel MG. O desafio de implementar as ações de saúde do trabalhador no SUS: a estratégia da Renast. Ciênc saúde coletiva. 2005;10(4):817-28.

32. Santos APL, Lacaz FAC. Saúde do Trabalhador no SUS: contexto, estratégias e desafios. In: Gomez CM; Machado JMH, Pena PGL, organizadores. (orgs.). Saúde do trabalhador na sociedade contemporânea brasileira. Rio de Janeiro: Fiocruz; 2011. 540 p.

33. Joazeiro EMG, Scherer MDA. Trabalho coletivo e transmissão de saberes na saúde: desafios da assistência e da formação. Tempus: Actas de Saúde Coletiva. 2011;6(2):279-91.

34. Brasil. Portaria n. ${ }^{\circ}$ 1.823/GM, de 23 de agosto de 2012. Institui a Política Nacional de Saúde do Trabalhador e da Trabalhadora. [Citado em 2012 dez 3]. Disponível em: http://bvsms.saude.gov.br/ bvs/saudelegis/gm/2012/prt1823_23_08_2012.html

35. Abuhab D, et al. O trabalho em equipe multiprofissional no CAPS III: um desafio. Rev gaúcha enferm. 2005;26(3):369-80.

36. Santos Filho SB, Barros MEB. O trabalho em saúde e o desafio da humanização: algumas estratégias de análise-intervenção. Tempus: Actas de Saúde Coletiva. 2011;6(2):101-22. 